\title{
Desenvolvimento de habilidades metatextuais e sua expressão na produção de textos de opinião ${ }^{1}$
}

\section{Metatextual knowledge development and its expression in the production of opinion writing}

\author{
Luciana Ribeiro Pinheiro ${ }^{2}$ \\ Sandra Regina Kirchner Guimarães ${ }^{2}$
}

\begin{abstract}
RESUMO
$\mathrm{O}$ artigo apresenta e discute dados do aprimoramento da capacidade de escrita a partir da reflexão sobre a aprendizagem das especificidades próprias da linguagem argumentativa. Realizou-se uma pesquisa de intervenção para o desenvolvimento da capacidade de gestão consciente do uso de marcas linguísticas da argumentação (operadores argumentativos e organizacionais). A escrita dos participantes do estudo - 18 alunos do $5^{\circ}$ ano do ensino fundamental de uma escola pública - foi analisada considerando-se dois aspectos: a) A relação entre os conhecimentos linguísticos relativos à coerência e à coesão e o aperfeiçoamento da escrita; b) A apropriação das especificidades tipológicas concernentes à escrita argumentativa. $\mathrm{O}$ estudo revelou que a decisão de usar os elementos constitutivos de um texto de opinião (argumento, contra-argumento, resposta) não é o único fator que orienta as produções textuais. Um importante fator evidenciado nas etapas de produção está relacionado ao tema e à forma como ele é apresentado aos participantes. Assim, verificou-se que o texto é mais bem desenvolvido
\end{abstract}

\section{DOI: $10.1590 / 0104-4060.48310$}

1 Este artigo é baseado em parte da Tese de Doutorado da primeira autora, com apoio da Coordenação de Aperfeiçoamento de Pessoal de Nível Superior (CAPES), sob orientação da segunda, apresentada ao Programa de Pós-Graduação em Educação da Universidade Federal do Paraná. Nossos agradecimentos à Secretaria Municipal de São José dos Pinhais, à escola e à professora que colaboram com esta pesquisa e, principalmente, aos estudantes, pela sua valiosa colaboração.

2 Universidade Federal do Paraná. Programa de Pós-Graduação em Educação. Curitiba, Paraná, Brasil. Rua General Carneiro, n 460. CEP: 80060-150.E-mails: lucianarp14@gmail.com e srkguimaraes@uol.com.br 
quando o tema proposto possibilita a criação de um espaço de negociação de divergências na produção textual. Entretanto, a realização de intervenções didático-pedagógicas possibilitou que os estudantes refletissem sobre os elementos da "estrutura argumentativa", o que resultou em um aumento de suas habilidades metatextuais e, consequentemente, maior capacidade no que se refere à produção deste gênero de texto.

Palavras-chave: habilidade metatextual; escrita argumentativa; texto de opinião.

\begin{abstract}
The article shows and discusses data from the improvement of the writing ability based on reflections about the learning of argumentative language and its specificities. This study performed an interventional research to develop the ability to handle linguistic features of argumentation consciously (argumentative operators and organizing operators). Participants were 18 elementary school students from a public school enrolled at the $5^{\text {th }}$ grade. The writing ability of the students was analyzed based on two main aspects: a) The association between the linguistic competence concerning coherence and cohesion and the improvement of the writing ability; b) The acquisition of the typological specificities regarding argumentative writing. According to the results, the decision to use the elements of an opinion text (argument, counterargument, response) is not the only factor that guides the process of producing a text. In addition, another important element highlighted in the process of producing a text is related to the theme and how it is presented to the students. Thus, it was found that the text is better developed when the theme enables a space for negotiating the divergences during the process of producing a text. However, didactic interventions provide the means for students to reflect about the elements of the "argumentative structure", resulting in the improvement of metatextual knowledge and a better capacity with regard to the production of this type of text.
\end{abstract}

Keywords: metatextual knowledge; argumentative writing; opinion text.

\title{
Introdução
}

Nos últimos 40 anos houve um considerável avanço nos conhecimentos acerca da metalinguagem. Uma vasta produção científica foi apresentada, apontando a existência de uma forte relação entre o desenvolvimento (nível) das habilidades metalinguísticas e a aprendizagem inicial da leitura e da escrita 
e seu posterior aperfeiçoamento. As evidências empíricas sugerem a necessidade de sistematização de intervenções pedagógicas que tornem os elementos da estrutura linguística dos textos objeto de reflexão, tendo em vista que o uso intencional de aspectos fonológicos, lexicais, morfológicos, sintáticos e semânticos da linguagem demanda o domínio de habilidades específicas. Assim, destaca-se a importância do ensino explícito dos aspectos linguísticos com vistas a desenvolver as habilidades metalinguísticas, pois a capacidade de leitura e escrita está intrinsecamente relacionada ao autocontrole e manipulação consciente dos tratamentos linguísticos.

Nessa perspectiva, um dos primeiros trabalhos mais expressivos mencionando as habilidades metalinguísticas foi publicado por Gombert (1992). Nessa obra, o autor postula a existência de operações metatextuais que envolvem o controle deliberado da estrutura prototípica e dos elementos que constituem tipos específicos de textos. Este tipo particular de funcionamento metalinguístico pode ser chamado de habilidade metatextual ${ }^{3}$.

Ainda de acordo com Gombert (1992), as habilidades metatextuais possibilitam ao indivíduo tomar o texto como objeto de análise e de reflexão deliberada, direcionando a sua atenção para a estrutura do texto, suas propriedades constituintes, as convenções linguísticas e marcadores, a atenção deve recair sobre o texto em si mesmo, e não sobre a sua função comunicativa. Ou seja, a atenção é voltada para o texto, em sua inteireza, abarcando todas as especificidades intralinguísticas, tornando-se alvo de reflexão tanto em seus aspectos microlinguísticos (reflexão sobre o emprego de coesivos, marcas de pontuação, etc.) como macrolinguísticos (análise dos conteúdos presentes no texto, reflexão sobre formas linguísticas e elementos que caracterizam diferentes tipos de textos, etc.), como apontam Pinheiro e Leitão (2007) e Pinheiro e Guimarães (2013).

No Brasil, a habilidade metatextual começa a ser pesquisada no final da década de 1990 e início de 2000 (SPINILLO, 1996, 2001, 2009; SPINILLO; SIMÕES, 2003; FERREIRA; SPINILLO, 2003; PINHEIRO; LEITÃO, 2007; PINHEIRO, 2012; PINHEIRO; GUIMARÃES, 2013), sendo que os trabalhos ainda são poucos, conforme apontou Mota (2009). Assim, essa temática

3 Uma das primeiras pesquisadoras a investigar a temática no Brasil foi Alina Spinillo (1996, 2001, 2009). A autora (SPINILLO, em comunicação pessoal, 09/05/2016) utiliza o termo "consciência metatextual" para referir-se à habilidade metatextual por analogia ao termo "metalinguistic awareness", utilizado por Tunmer, Pratt e Herriman (1984) no livro intitulado "Metalinguistic awareness in children: Theory, research and implications". Segundo Spinillo (comunicação pessoal, 26/08/2016), além dessa analogia, o uso do termo "consciência metatextual", traduzido do inglês "metatextual awareness", também é adotado por outros estudiosos da área em publicações em língua inglesa. (e.g., TINDAL; MARSTON, 1996; RUSSEL, 2000; BERMAN; KATZENBERGER, 2004; WALSH, 2006; WANG, 2011; THURLOW, 2012; SIMPSON; WALSH; ROWSELL, 2013). 
reveste-se de importância por clarificar a existência de processos e estratégias linguísticas que, quando conscientes, auxiliam no controle e manipulação de elementos linguísticos essenciais ao bom desempenho na produção de textos.

No que se refere especificamente ao texto de opinião, Santos (2005) defende sua inserção no campo da argumentação dialética, ou seja, da Retórica. A finalidade comunicativa é persuadir, é produzir consenso e buscar a adesão do outro a partir do embate de ideias. É uma ação de linguagem cujo objetivo é argumentar a favor da posição assumida, com a qual o sujeito se compromete. Segundo Bränkling (2000), é um gênero do discurso que visa o convencimento do outro, intencionando que este assuma a ideia que está sendo defendida. Busca-se influenciá-lo por meio da argumentação a favor de um ponto de vista emitido pelo produtor, e da refutação de possíveis ideias divergentes. Para isso, é preciso considerar a existência do outro, colocar-se no lugar desse outro, antecipando suas posições para conseguir refutar contraposições.

A competência na escrita de um texto de opinião implica em realizar uma interação comunicativa com interlocutores que não estão diretamente presentes quando da elaboração dos enunciados. A participação de possíveis interlocutores ocorre num contexto imaginário, tornando indispensável gerir conscientemente o sentido de um enunciado para que a progressão discursiva ocorra. A existência do outro é fator que caracteriza esse gênero como um espaço eminentemente de intercâmbio de ideias, viabilizado pelo dialogismo.

Quanto a esse aspecto, o reconhecimento da diversidade funcional e discursiva impõe a seleção de elementos linguísticos, como os conectivos, que possibilitem o encadeamento de ideais. E essa seleção influenciará na qualidade da interpretação discursiva por estabelecer uma relação semântica entre as partes do texto. A produção discursiva, portanto, não pode ser entendida como resultado de uma lógica de causalidade, automática e previsível, constituída de movimentos uniformes (locutor emite uma mensagem e o interlocutor simplesmente a decodifica/interpreta).

É incontestável a natureza dialógica da produção argumentativa, especialmente do texto de opinião. O dialogismo neste gênero textual lhe confere diferentes funções comunicativas que podem ocorrer simultaneamente: apresentar pensamentos que revelam a posição assumida pelo autor e as reflexões críticas acerca de uma temática; representar contexto de interações entre ideias divergentes (ou similares, buscando o reforço do ponto de vista assumido); assumir o papel de instrumento comunicativo para a difusão e defesa de opiniões, visando à persuasão; fomentar discussões em que a dinâmica de pensamentos reflexivos pode acarretar mudanças em pontos de vista. Assim, pode-se considerar que o texto de opinião tem como finalidade primordial o diálogo envolvendo o autor e interlocutores. 
Destacando o papel do dialogismo na argumentação, Leitão (2003) afirma que são as situações sociais concretas que determinam o nível de elaboração e de explicitação na produção de um discurso argumentativo, e não, necessariamente, um tipo de normatividade, de determinação sequencial de um texto. Ainda segundo Leitão $(2001,2007)$, a produção argumentativa é composta por uma unidade de análise, constituída por três elementos: argumentos, contra-argumentos e resposta. Estes elementos são tomados em conjunto formando uma unidade de análise porque ao se isolar qualquer um deles - ou subconjunto deles - não se torna possível capturar "[...] o processo de revisão de perspectiva que a argumentação põe em marcha”. (LEITÃO, 2007, p. 84). A autora destaca que qualquer um desses elementos, por si mesmo, possui três dimensões específicas: “[...] a- implementação da própria atividade argumentativa (função discursiva); b- instalação do processo de revisão (função psicológica); c- (trans)formação do conhecimento (função epistêmica)". (LEITÃO, 2007, p. 84).

Além de explicitar os elementos composicionais da estrutura prototípica do texto de opinião, as marcas linguísticas são imprescindíveis para esse gênero. Segundo Pinheiro e Guimarães (2013), a escolha de marcas linguísticas está relacionada às ideias que se pretende defender. Assim, é preciso instaurar marcas linguísticas na escrita a partir de condições enunciativas específicas capazes de atender o seu propósito persuasivo. $\mathrm{O}$ embate de ideais se manifesta em um contexto cujas ações linguísticas visam solucionar possíveis divergências de opinião, tendo como resultado desejado a adesão do outro (no caso, o leitor) à posição assumida pelo autor. Para tanto, especialmente no texto de opinião, a coerência e a coesão textual clarificarão as ideias defendidas.

No que se refere à coerência e à coesão, Koch (2009) e Koch e Elias (2008) afirmam que as concepções sobre coerência e coesão sofreram alterações ao longo do tempo. A princípio, confundiam-se os conceitos, mas na medida em que as concepções de texto sofreram modificações, estes conceitos foram sendo delineados com maior clareza, diferenciando-se de maneira decisiva. Koch e Travaglia (2007) defendem que a coerência é responsável pela textualidade, possibilitando que uma sequência linguística, sequência de frases, seja percebida pelo interlocutor como um texto, uma unidade significativa global. Chagas (2007, p. 215) propõe que "[...] a coerência apresenta-se como o princípio da interpretabilidade do texto, envolvendo fatores de ordem cognitiva, interacional e linguística." Nesse caso, este princípio está relacionado à boa estrutura do texto, estabelecendo a unidade de sentido e se caracterizando como ato global, ou seja, o texto como um todo. A composição da textualidade ocorre pelo entrelace entre a coerência e a coesão. A coesão corresponde às marcas linguísticas usadas para dar pistas que auxiliam os interlocutores na representação mental do texto. (CHAGAS, 2007). De acordo com Koch (2009), coesão se refere à maneira 
como os elementos linguísticos que estão presentes na superfície do texto se interligam por meio de recursos também linguísticos, formando sequências que veiculam sentido, constituindo, portanto, a tessitura textual. Marcuschi (2008) destaca que os processos de coesão não devem ser considerados simples princípios sintáticos, uma vez que se materializam por meio de elementos presentes na superfície do texto que são responsáveis pela sequência do texto.

Entre os procedimentos linguísticos que precisam ser adotados na produção de texto de opinião, destaca-se a escolha de operadores argumentativos e operadores organizacionais que orientem a sequência discursiva, apontando a representação argumentativa e o sentido dos enunciados. Por isso, as interações sociocomunicativas que se manifestam por meio da produção desse gênero específico requerem o uso lógico de elementos textuais, especialmente de elos coesivos.

Inserido no contexto teórico apresentado, este estudo tem como objetivo discutir os efeitos de uma intervenção pedagógica cuja finalidade se pautou no desenvolvimento de habilidades metatextuais de alunos do $5^{\circ}$ ano do ensino fundamental. $\mathrm{O}$ delineamento da investigação teve como finalidade buscar elementos que pudessem confirmar (ou infirmar) a hipótese de que os conhecimentos concernentes à estrutura de textos de opinião, trabalhados em uma sequência didática, seriam apropriados pelos alunos possibilitando-lhes maior competência na produção desses textos. As atividades propostas visavam o controle intencional na seleção e uso de operadores argumentativos e operadores organizacionais na produção de textos de opinião, e aspectos relacionados à estrutura do gênero (argumentos, contra-argumentos, resposta).

\section{Método}

A pesquisa caracteriza-se como exploratório-descritiva e teve um enfoque qualitativo. $\mathrm{O}$ estudo foi realizado numa escola de pequeno porte, de uma rede pública municipal. Participaram da pesquisa dezoito alunos que frequentavam o $5^{\circ}$ ano do ensino fundamental, com idades variando entre 10 e 14 anos ( $\mathrm{dp}=$ $1,35)$. Do total de dezoito alunos, oito deles apresentavam histórico de reprovações escolares.

Como instrumento de intervenção e procedimento principal para a coleta de dados, realizou-se uma sequência didática fundamentada em Dolz, Noverraz e Schneuwly (2004) e em Bronckart (1999). Salienta-se que a sequência didática "[...] é um conjunto de atividades escolares organizadas, de maneira sistemática, em torno de um gênero textual oral ou escrito". (DOLZ; NOVERRAZ; 
SCHNEUWLY, 2004, p. 97). O instrumento de intervenção e coleta de dados (sequência didática) envolveu diversas atividades elaboradas para este estudo.

Na primeira etapa, houve a apresentação da situação de necessidade de produção de texto de opinião e os participantes foram incentivados a realizar uma produção inicial. Na sequência, foram implementados três módulos de atividades: o primeiro módulo, Conhecendo o texto argumentativo/de opinião, foi subdividido em cinco oficinas; o segundo módulo, Analisando as produções - estrutura, coesão e coerência textuais, foi subdividido em duas oficinas; e no terceiro módulo, Produzindo textos de opinião, houve apenas uma oficina de produção textual. Assim, no total da intervenção pedagógica, foram realizadas oito oficinas.

A escolha por texto de opinião como gênero textual ocorreu em função da escassez de trabalhos que abordam textos argumentativos nos anos iniciais do ensino fundamental. (LEITÃO; ALMEIDA, 2000; SOUZA, 2003; FERREIRA; SPINILLO, 2003; PINHEIRO, 2012; PINHEIRO; GUIMARÃES, 2013).

A seguir serão apresentados e analisados, em duas seções, os dados obtidos na intervenção pedagógica: A primeira seção foi denominada “A relação entre os conhecimentos linguísticos relativos à coerência, coesão e o aperfeiçoamento da escrita"; a segunda seção denominada "A apropriação das especificidades tipológicas concernentes à escrita argumentativa", e, na sequência, apresenta-se e se analisa as produções de um aluno, Bento ${ }^{4}$, como exemplo. Por fim, são apresentadas considerações finais.

\section{A relação entre os conhecimentos linguísticos relativos à coerência e à coesão e o aperfeiçoamento da escrita}

Os dados aqui apresentados são provenientes dos textos produzidos em quatro momentos do estudo: produção inicial (realizada antes da intervenção); produção dirigida (atividade com explicações detalhadas sobre a produção de um texto de opinião); produção não dirigida (produção sem intervenção da professora); e reescrita (da produção inicial), em que se verificou a ocorrência do uso de palavras e expressões relativas aos conectivos.

As análises realizadas revelaram que, entre as conjunções (operadores argumentativos), as mais usadas na produção inicial foram: conjunção aditiva " $e$ "; e a conjunção causal "porque". Após a intervenção, verificou-se a diminuição do

4 Foi atribuído um nome fictício ao estudante para preservar sua identidade. 
emprego da conjunção causal "porque" na reescrita do texto. Outro ponto que merece destaque foi o uso excessivo da conjunção aditiva "e" na produção não dirigida e a não ocorrência do uso de conjunções que expressam comparações e finalidade. A frequência do uso da conjunção "se" é semelhante na produção inicial, na produção não dirigida e na reescrita. A única exceção foi os textos da produção dirigida, em que esta conjunção apareceu com mais frequência.

Observou-se que, considerando os quatro momentos de produção, os estudantes usavam, basicamente, quatro tipos de organizadores argumentativos: "mas", "e", "se", e "porque". Foi possível notar três situações cujos aspectos são dignos de nota: o excessivo uso do "e" na produção não dirigida; a diminuição do uso do "porque" quando se compara a produção inicial e a reescrita, e a alta frequência do uso da conjunção "se", nos vários momentos de produção. Esta última situação revela que os estudantes não se apropriaram deste operador de forma a empregá-lo adequadamente. Além disso, as análises revelaram que, no transcorrer de todo o estudo, não houve uma alteração significativa no uso de expressões que ajudavam a reforçar ou esclarecer melhor a ideia que o escritor estava apresentando. Encontrou-se a expressão "Por exemplo" usada por uma estudante na produção inicial, que foi mantida por ela no texto de produção não dirigida e na reescrita.

Quanto às expressões que dão noção de tempo e espaço e que apareceram com maior frequência estão: "Em primeiro lugar..." e "Em segundo lugar...", ambas eram adotadas com maior frequência na produção não dirigida e na reescrita. Computaram-se essas expressões que dão noção de tempo e espaço de forma apropriada. Por exemplo, a expressão "Em primeiro lugar..." foi empregada em situações em que, na sequência do texto, apareciam expressões pertencentes a esse mesmo grupo linguístico, como: em "segundo lugar", ou, "como vimos". Além disso, a expressão "Em primeiro lugar..." também foi utilizada para anunciar a tomada de posição do aluno em relação ao tema. Nestes casos, computou-se como expressão metalinguística que expressa o ponto de vista do autor.

\section{A apropriação das especificidades tipológicas concernentes à escrita argumentativa}

Nesta seção, analisa-se a presença de elementos que constituem a estrutura de um texto de opinião. O corpus analisado consistiu nas produções dos alunos em três momentos da sequência didática: produção inicial, produção dirigida e produção não dirigida. 
O ponto de partida para essa análise foi a hipótese de que os conhecimentos concernentes à estrutura de textos de opinião, abordados na sequência didática, seriam apropriados pelos participantes, favorecendo o aprimoramento da sua produção escrita. Para o exame dos textos utilizou-se a unidade de análise proposta por Leitão $(2001,2007)$, que é constituída por três elementos básicos: argumento, contra-argumento e resposta. Importante ressaltar que com esta análise buscou-se verificar a presença/ausência desses elementos e examinar possíveis causas para o seu uso ou não uso.

A produção inicial teve como tema um questionamento: "bater nas crianças resolve?". E nessa primeira produção houve um resultado inesperado. A maioria dos participantes $(56 \%)$ produziu textos contendo argumentos, contra-argumentos e resposta sem que tenham vivenciado intervenções acerca da escrita argumentativa. Buscando explicar os possíveis motivos para esse resultado levantou-se duas hipóteses, ambas relacionadas ao tema proposto. A primeira hipótese refere-se à exposição do tema em forma de uma pergunta. $\mathrm{O}$ tema proposto como pergunta teria funcionado como um convite ao debate, à discussão, à reflexão sobre os pontos de vista, impondo a necessidade de emissão de um ponto de vista, elemento esse constituinte da estrutura do texto. A segunda hipótese, a própria temática escolhida. A representação de situação real transposta para o contexto de produção escrita mostrou-se conveniente para se discutir um tema que aflige muitas crianças.

As análises revelam que muitos alunos consideraram essa produção como um lugar onde tinham a oportunidade de negociar pontos de vista, emitir juízo de valores, rever crenças. Com isso, puderam reafirmar aos interlocutores que não se deve bater em crianças. Muitas foram as justificativas plausíveis, muitas foram as estratégias de persuasão. Verificou-se ainda que todos os estudantes, sem exceção, que apresentaram contra-argumentos, o fizeram a partir do reconhecimento da oposição representada pela atitude dos pais.

Os resultados relativos à inserção de contra-argumentos se encontram em consonância com a proposição de Pinheiro e Leitão (2007): as vozes de oposição aparecem em um discurso argumentativo quando o proponente é capaz de antecipar e responder a posições contrárias à posição defendida.

De modo geral, a produção dirigida foi a atividade que possibilitou melhor desempenho dos estudantes. Nesta atividade o tema também se referia a algo do cotidiano vivenciado pelos estudantes: o uso do uniforme escolar deve ser obrigatório? Um grande número de participantes (67\%) produziu textos que contemplavam os elementos constitutivos do texto de opinião. Destaca-se que antes de realizarem a produção escrita, os estudantes vivenciaram diversas experiências relativas ao tema. Fizeram entrevistas na escola, pesquisaram e debateram sobre a importância do uso do uniforme, discutiram posicionamentos 
diferentes e perceberam que os temas polêmicos geram uma zona de conflito discursivo. Deste modo, é possível afirmar que o conhecimento dos estudantes acerca de diferentes posições sobre o tema antes da produção foi um elemento decisivo na qualidade argumentativa dos textos. Em outras palavras, é provável que o contexto de produção, designado por Bronckart (1999, p. 93) como “[...] o conjunto dos parâmetros que podem exercer uma influência sobre a forma como um texto é organizado", tenha influenciado positivamente na produção dos textos.

De outra parte, a produção não dirigida foi proposta a partir da temática "a importância de trocar o carro pela bicicleta". Ao analisar as produções foi possível perceber que a compreensão feita pelos estudantes foi apenas a de cumprir com uma atividade escolar. Pode-se dizer que os estudantes não se sentiram motivados a ponto de transformarem a escrita em um espaço de negociação, de conflito de ideais, ou um instrumento de ação cidadã. Não houve qualquer referência textual extraescolar. A escrita constituiu-se restritamente como um modo de escrever por escrever, na qual simplesmente cumpre-se a exigência/ determinação institucional.

Nota-se que na produção não dirigida, realizada sem qualquer mediação da professora, os resultados não foram satisfatórios. Apenas $28 \%$ do total de estudantes produziram textos contendo todos os elementos constitutivos do texto de opinião. Nesta atividade, o desempenho pode ter sido resultante de um conjunto de fatores, entre eles: a relação dos estudantes com o tema proposto (aparentemente este era um tema sobre o qual as crianças não tinham conhecimentos prévios suficientes para o debate) e a forma afirmativa como o tema foi apresentado, fazendo com que ele não fosse percebido como polêmico. O tema parece ter sido algo distante da realidade e interesse dos estudantes, como havia sido notado em relação às produções relativas aos outros temas.

Souza (2003) afirma que a escrita de textos de opinião na escola encontra-se sujeitada às condições de produção. Neste sentido, “[...] há interferências de um conjunto de fatores, e não apenas de uma instrução escrita ou de uma situação de produção momentânea, desvinculada de um trabalho anterior". (SOUZA, 2003, p. 179). Souza (2003) sustenta-se em Golder ${ }^{5}$ (1996) para defender que o tema pode ser considerado um dos principais elementos para viabilizar a produção de textos de opinião. Por isso, “[...] deve ser aceitável socialmente, instigar debates e desacordos, ser significativo e possibilitar soluções de problemas vivenciados pelos alunos". (SOUZA, 2003, p. 124). Os resultados encontrados corroboram esta posição, pois apontam que o tema e a forma como este é apresentado influenciam a qualidade da escrita. Entretanto,

5 GOLDER, C. Le développement des discours argumentatifs. Paris: Delachaux et Niestlé, 1996. 
o tema não pode ser tomado como o único fator determinante para desencadear uma escrita argumentativa de qualidade.

O desenvolvimento dos estudantes nas atividades de produção escrita não ocorreu de forma linear, apresentando uma melhora gradual no desempenho, embora este tenha ocorrido de forma descontínua. Souza (2003, p. 174), a partir de seus estudos com crianças no processo de alfabetização, constatou que "[...] na produção de textos um processo irregular, descontínuo, heterogêneo, e permeado de avanços e retrocessos - um dia o texto tem legibilidade, no outro não pode ser lido. Portanto, o desenvolvimento da escrita inicial não pode ser visto como fase, porque não há uma evolução linear". No caso, acredita-se que essa situação possa ocorrer não somente durante a aprendizagem inicial da escrita como pesquisado pela autora, mas em todo o processo de desenvolvimento da capacidade de escrita.

Esses resultados coadunam aos estudos realizados por Pinheiro e Leitão (2007) sobre a relação entre a habilidade metatextual relativa aos elementos constituintes básicos da argumentação (argumento, contra-argumento e resposta) e a propensão dos estudantes a incluir estes elementos nas suas produções de textos. De modo geral, os resultados aqui apresentados, da mesma forma que aqueles do estudo de Pinheiro e Leitão (2007), apontam para "[...] a consideração de outros fatores, que não estritamente a consciência do 'esquema argumentativo', na decisão do escritor de incluir, ou não, num texto qualquer dos elementos teoricamente definidos como parte do "esquema argumentativo prototípico"”. (PINHEIRO; LEITÃO, 2007, p. 430). As autoras baseiam-se em Leitão (2003) para afirmar que a decisão de incluir oposição (contra-argumentos) em um texto parece depender de um tipo de consciência retórica “[...] que permita ao escritor avaliar antecipação/rebatimento de contra-argumentos como estratégia que pode ser retoricamente efetiva no alcance do propósito persuasivo do texto." (PINHEIRO; LEITÃO, 2007, p. 430).

\section{Análise e discussão sobre as produções do aluno Bento}

Com a finalidade de exemplificar parte do exposto, serão apresentadas duas produções realizadas por Bento - escrita e reescrita - que destacam o movimento realizado por ele durante o percurso da sequência didática. Serão analisadas as estratégias empreendidas pelo estudante na organização prototípica dos textos e o uso de operadores argumentativos e operadores organizacionais.

6 LEITÃO, S. Evaluating and selecting counterarguments. Studies of children's rhetorical awareness. Written Communication, v. 20, n. 3, p. 269-306, 2003. 


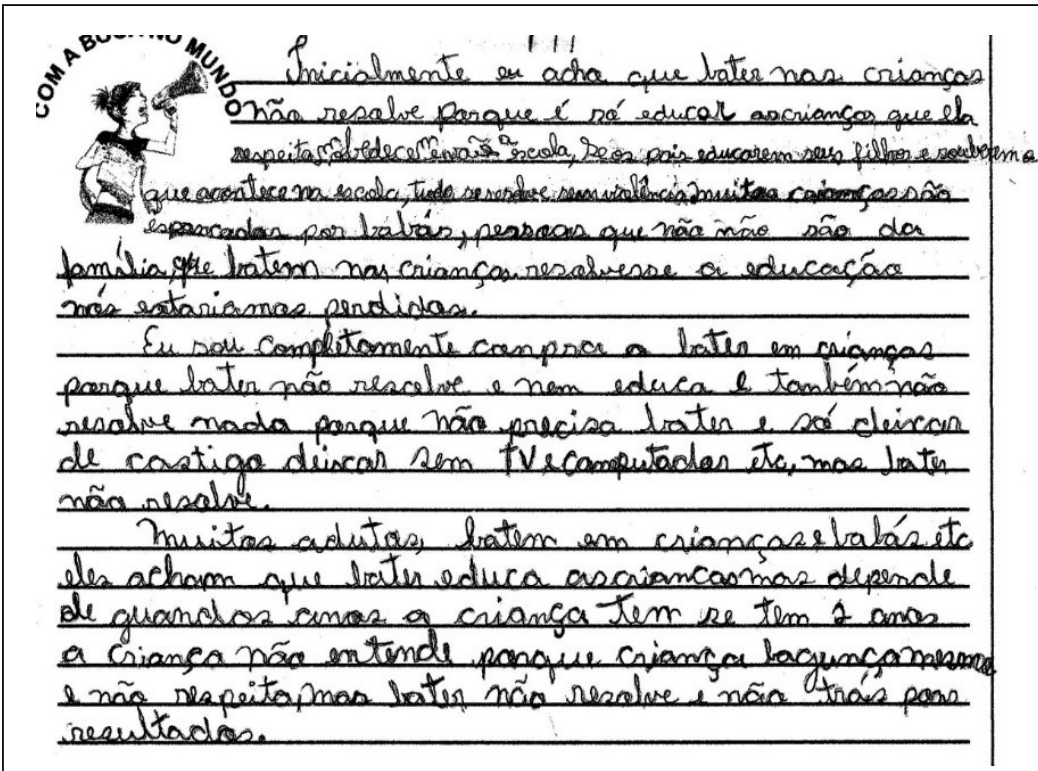

\section{ARGUMENTO $\rightarrow$ CONTRA-ARGUMENTO}

ponto de vista $\rightarrow$ justificativas $\rightarrow$ ponto de vista $\rightarrow$ Reconhecimento de elemento opositor $\rightarrow$ Ponto de vista

Inicialmente eu acho que bater nas crianças não resolve porque é só educar as crianças, que ela respeitam obedecem e vão a escola, se os pais educarem seus filhos e souberem o que acontece na escola tudo se resolve sem violência. Muitas crianças são espancadas por babás, pessoas que não são da família, que batem [se bater] nas crianças resolvesse a educação nós estaríamos perdidos.

\section{ARGUMENTO \\ ponto de vista $\rightarrow$ justificativas $\rightarrow$ ponto de vista}

Eu sou completamente conpra o bater em crianças porque bater não resolve e nem educa e também não resolve nada porque não precisa bater e [é] só deixar de castigo deixar sem TV e computador etc, mas bater não resolve.

\section{CONTRA-ARGUMENTO, ARGUMENTO E RESPOSTA}

Reconhecimento de elemento opositor $\rightarrow$ ponto de vista e justificativa $\rightarrow$ resposta

Muitos adultos batem em crianças e babás etc eles acham que bater educa as crianças mas depende de quantos anos a criança tem se tem 2 anos a criança não entende porque criança bagunça mesmo e não tem respeito, mas bater não resolve e não trás bons resultados.

FONTE: Pinheiro (2012, p. 152). 
Na produção inicial, Bento começa emitindo o seu ponto de vista sobre o assunto e justificando-o. O estudante estrutura o parágrafo inicial assumindo o ponto de vista de que bater nas crianças não revolve. Justifica defendendo a ideia de que basta educá-las que irão obedecer e ir à escola. Reforça o seu ponto de vista e reconhece que há oposição quando apresenta o fato de que muitas crianças apanham de babás e pessoas que não são da família que acreditam na violência física como ações educativas. O parágrafo se encerra enfatizando mais uma vez o seu ponto de vista.

Quando Bento utiliza o operador organizacional metalinguístico (Inicialmente...) situa o interlocutor em relação ao seu ponto de vista, trazendo-o para o contexto da discussão. O argumento de Bento, "bater nas crianças não resolve" é sustentado por um operador argumentativo causal (porque) que convida o interlocutor a pensar sobre o assunto a partir das justificativas assumidas por ele (porque é só educar as crianças, que ela respeitam obedecem e vão a escola). Na sequência discursiva, o estudante usa o operador argumentativo que expressa uma condição (se) fazendo com que o interlocutor reflita sobre outras possibilidades de encaminhamento educativo, com o intuito de defender a ausência de práticas violentas. A ideia é reforçada com o argumento que vem após a utilização do operador argumentativo de adição " $e$ " (se os pais educarem seus filhos e souberem o que acontece na escola tudo se resolve sem violência). $\mathrm{Na}$ proposição sublinhada observa-se a intenção de adicionar mais um argumento para evidenciar a ideia de uma educação sem violência.

No segundo parágrafo, Bento realiza um deslocamento do seu ponto de vista para assumir também o lugar de justificativa, desdobrando a frase em ponto de vista e justificativa (Eu sou completamente conpra o bater em crianças porque bater não resolve e nem educa). Ao mencionar o seu ponto de vista mais uma vez, enfatiza o seu posicionamento (completamente contra), delimitando com veemência, no espaço de tensão dialógica, o seu lugar no embate de ideias. Para consolidar o seu ponto de vista, ele usa o operador argumentativo "porque" para explicar que a violência "não resolve". Ele usa o operador argumentativo " $e$ " para adicionar mais uma explicação, e, em seguida, o operador argumentativo "nem" com o intuito de excluir a ideia de que a violência educa. $\mathrm{O}$ estudante continua a sua sequência argumentativa utilizando mais uma vez o operador argumentativo " $e$ " e o "porque" com a finalidade de concatenar as frases. Acrescenta ainda justificativas com exemplos de possíveis ações educativas que considera não ser violentas e conclui reforçando mais uma vez o seu ponto de vista (mas bater não resolve.) usando o operador argumentativo "mas", que introduz uma oposição semântica ao enunciado anterior (e [é] só deixar de castigo deixar sem TV e computador etc). Bento fortalece os seus argumentos negociando com 
o interlocutor um caminho mais plausível para a educação apontando ações alternativas que, em sua opinião, geram melhor consequência educativa.

No terceiro e último parágrafo, Bento usa o seu ponto de vista com outra finalidade, a de construir a resposta ao conflito discursivo, reforçando o seu posicionamento e refutando possíveis opiniões dos seus opositores potenciais (pais e educadores adeptos ao uso de violência física para educar). Para tanto, estabelece o encadeamento de ideias fazendo uso de operadores argumentativos de oposição (mas), de adição (e) e de causalidade (porque). Nota-se que o estudante mantém os mesmos operadores argumentativos utilizados desde o primeiro parágrafo (Muitos adultos batem em crianças e babás etc eles acham que bater educa as crianças mas depende de quantos anos a criança tem se tem 2 anos a criança não entende porque criança bagunça mesmo e não tem respeito, mas bater não resolve e não trás bons resultados.), inclusive utilizando-os em alguns momentos no lugar de marcações gráficas (sinais de pontuação).

$\mathrm{Na}$ reescrita de Bento, apresentada no quadro a seguir, é possível constatar a preocupação em realizar melhorias na organização da sua escrita. Fez uso mais adequado dos operadores argumentativos e organizacionais e reestruturou elementos que compõem a estrutura tipológica do texto de opinião, aprimorando o encadeamento de ideias.

O primeiro movimento que o estudante realizou na tentativa de melhorar o texto foi trocar o operador organizacional metalinguístico que havia usado na produção inicial (Inicialmente) por outro (Diante de tudo). No texto inicial, o operador organizacional usado conduz o interlocutor diretamente ao ponto de vista assumido por Bento. A alteração realizada modifica a posição do escritor e do interlocutor, situando-os, num primeiro momento, em um contexto extratextual. O embate de ideias parte das informações de um contexto externo ao texto, sejam as informações jornalísticas (fictícias) presentes na atividade, sejam as experiências prévias de ambos. A reescrita revela a tentativa de progresso do estudante concernente à estrutura do gênero trabalhado. As alterações na disposição dos parágrafos e na organização dos enunciados configuram que o texto foi tomado como objeto de reflexão deliberada, sendo que a atenção foi voltada tanto para os aspectos macroestruturais como microlinguísticos que compõem o texto. O primeiro parágrafo do texto inicial, por exemplo, foi subdividido na reescrita em três parágrafos.

As produções contidas nos dois quadros apontam que Bento não realiza uma disposição de elementos característicos do gênero textual de forma linear, única e constante. A organização desses elementos depende da conveniência do estudante em tratá-los, seguindo um plano textual individual, específico para cada situação-contexto. Não há indícios de ter que apresentar uma sequência imposta. Não há uma tentativa de elaborar o texto seguindo os parâmetros de 


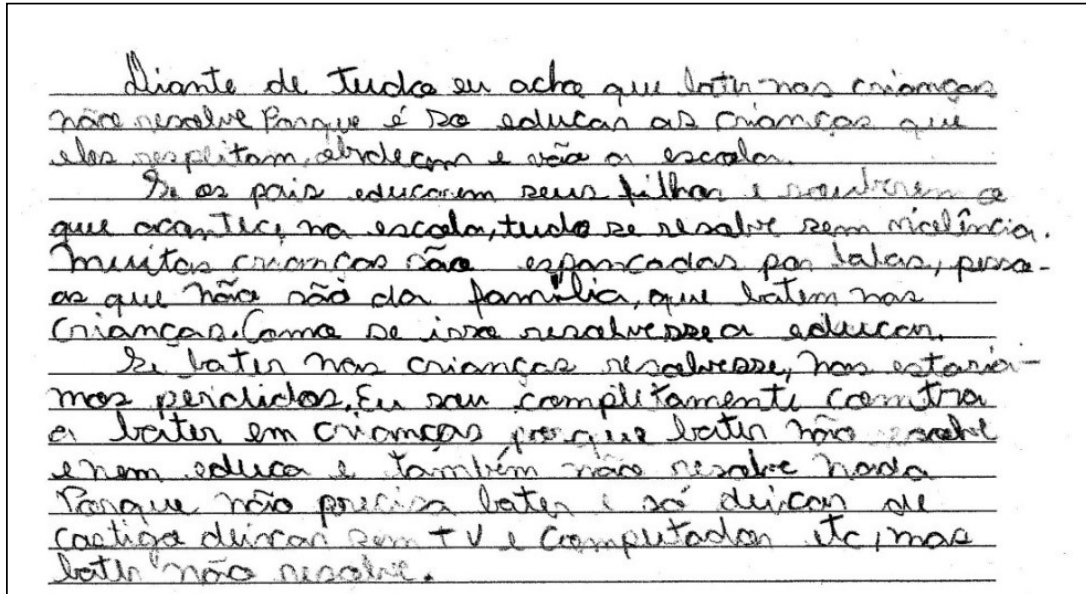

Lliante de tudce en acho que latir nos crimencon näa nescelve fonnue é so educan as criomson us

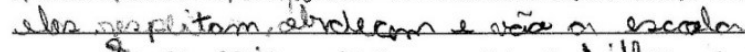

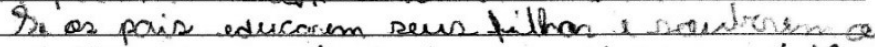
que acan ter, ma escalo, tudo se resalve rem vícilincia.

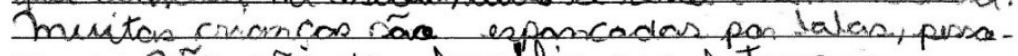
as que ráa nãa da familia, que batem has Giancari. Coma de inse sesalvessea educcon. se bater nas crioncas resaluease, has estariomos periclidos. Eer sau comple torrente com tra

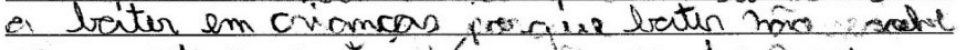

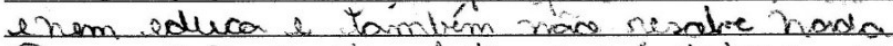
Provare mío porion bater i só deican de cactioge deirar por $t v$ e computadon tcimar both "mö́c nearivie.

\section{ARGUMENTO \\ ponto de vista $\rightarrow$ justificativas}

Diante de tudo eu acho que bater nas crianças não resolve porque é so educar as crianças que elas respeitam, obedecem e vão a escola.

\section{ARGUMENTO}

justificativas $\rightarrow$ ponto de vista

Se os pais educarem seus filhos e souberem o que acontece na escola, tudo se resolve sem violência.

\section{CONTRA-ARGUMENTO}

reconhecimento de elemento opositor

Muitas crianças são espancadas por babás, pessoas que não são da família que batem nas crianças. Como se isso resolvesse a educar [educação].

\section{ARGUMENTO $\rightarrow$ RESPOSTA \\ ponto de vista $\rightarrow$ justificativas $\rightarrow$ ponto de vista $\rightarrow$ resposta}

Se bater nas crianças resolvesse, nós estaríamos perdidos. Eu sou completamente comtra o bater em crianças porque bater não resolve e nem educa e também não resolve nada porque não precisa bater e só deixar de castigo deixar sem TV e computador etc, mas bater não resolve.

FONTE: Pinheiro (2012, p. 157). 
um modelo específico, tentando seguir uma imposição ordenada na relação entre as partes constitutivas dos textos. No entanto, as produções formam unidades textuais que se adequam ao gênero proposto.

A reelaboração escrita mostra que Bento direciona-se para uma autonomia na escrita, o que lhe garante maior coerência na tomada de decisão de retirar, incluir ou de mudar a sequência de enunciados. Assim, demonstra manipular conscientemente partes do texto, sem alterar o sentido estabelecido por ele. Percebe-se o deslocamento de enunciados após identificar pontos incompletos e confusos.

No que diz respeito aos elementos de coesão usados, é possível afirmar que Bento compreende a função dos operadores usados por ele para organizar as informações e para estruturar a argumentação. Contudo, não é possível afirmar que o uso desses operadores tenha ocorrido de forma deliberada e consciente com o intuito de determinar o valor argumentativo dos enunciados. Infere-se que o desconhecimento da determinação do valor semântico de cada um dos operadores argumentativos seja o principal motivo pelo qual não houve inclusão de novos operadores ou mudanças daqueles elementos conectivos na reescrita. Bento manteve os mesmos operadores e com os mesmos valores semânticos nas duas produções. O uso do operador argumentativo "mas", por exemplo, ora apareceu com a função de contrapor argumentos, ora para acrescentar enunciados. O operador argumentativo mais usado foi o " $e$ ", com a intenção principal de somar argumentos a favor do ponto de vista assumido. O operador argumentativo que indica causalidade "porque" permaneceu sendo usado para explicar, ou intensificar, os motivos que levam o estudante a assumir determinado ponto de vista.

Apesar dos enunciados serem idênticos nas duas produções, verifica-se na reescrita de Bento um aprimoramento do texto, com a finalidade de tornar a escrita mais legível. Assim, os resultados sugerem que no processo de aprendizagem de um gênero textual a finalidade comunicativa parece delinear a escolha de elementos de coesão e a estrutura organizacional do texto.

Em última análise, os resultados deste estudo sugerem que as produções textuais são guiadas pelos conhecimentos que os estudantes têm sobre a estrutura do texto, pelo fluxo de ideias sobre o tema e pelo envolvimento deles com a temática, que se fundamentam nas interações estabelecidas socialmente. 


\section{Considerações finais}

O desenvolvimento de habilidades metatextuais, tanto no que se refere aos aspectos macrolinguísticos quanto aos microlinguísticos, é um tema que merece atenção. Escrever bem um texto argumentativo não depende apenas de conhecimentos acerca de sua estrutura prototípica. É imprescindível a realização de procedimentos linguísticos que colaboram com o discurso argumentativo. Nesse caso, o uso intencional de elementos de coesão conectiva, os operadores argumentativos e os operadores organizacionais, garantem a força argumentativa, determinando o valor semântico e persuasivo dos enunciados. Por isso, o uso desses elementos precisa ser realizado a partir de uma reflexão acerca da intenção argumentativa que se pretende estabelecer. Partindo desses pressupostos, este estudo visou discutir os efeitos de uma intervenção pedagógica cuja finalidade se pautou no desenvolvimento de habilidades metatextuais de alunos do $5^{\circ}$ ano do ensino fundamental.

O estudo revelou que a decisão de usar os elementos constitutivos de um texto de opinião pode estar relacionada a outros fatores que extrapolam o conhecimento sobre as partes constitutivas desse gênero textual. Um fator evidenciado nas etapas de produções que interfere diretamente sobre a escrita dos alunos é o tema e está relacionado à forma como é apresentado, o que ele gera de motivação, o que ele propicia como elemento de reflexão e como pode mobilizar a capacidade de produção escrita dos alunos. Pode-se concluir que o tema é capaz de trazer à tona manifestações explicitadas na escrita conforme o significado que tenha para os alunos. No caso do artigo de opinião, o tema deve estar relacionado à vida dos alunos, representando um problema a ser resolvido, contendo a possibilidade de dimensões controversas nas quais a resolução pode estar ao alcance do escritor, via interlocução. A motivação parece ter relação com a possibilidade de debates que tenham efeitos na vida prática. Que as vozes dos alunos, ali traduzidos em palavras escritas, sejam ecoadas nos contextos aos quais os temas da escrita se referem. Por isso, sugere-se que nas intervenções pedagógicas voltadas para a produção de textos é fundamental atentar para a escolha dos temas, bem como para a forma como eles são apresentados.

Por fim, embora se tenha ciência dos limites desta investigação, principalmente relativas ao tempo de intervenção e número de participantes, seus resultados sugerem que intervenções pedagógicas que utilizem sequências didáticas constituem-se adequado encaminhamento metodológico para o desenvolvimento das habilidades metatextuais dos estudantes e, consequente, aprimoramento da sua capacidade de produção de textos. 


\section{REFERÊNCIAS}

BERMAN, R. A.; KATZENBERGER, I. Form and function in introducing narrative and expository texts: A developmental perspective. Discourse Processes, v. 38, n. 1, p. 57-94, 2004.

BRÄNKLING, K. L. Trabalhando com artigos de opinião: Re-visitando o eu no exercício da (re)significação da palavra do outro. In: ROJO, R. (Org.). A prática da linguagem em sala de aula: Praticando os PCNs. São Paulo: EDUC / Campinas: Mercado de Letras, 2000. p. 221-248.

BRONCKART, J. P. Atividade de linguagem, textos e discursos: Por um interacionismo sócio-discursivo. São Paulo: EDUC, 1999.

CHAGAS, C. E. Cognição e texto: A coesão e a coerência textuais. Ciênc. cogn. [on-line], v. 12, p. 214-218, 2007.

DOLZ, J.; NOVERRAZ, M.; SCHNEUWLY, B. Sequências didáticas para o oral e a escrita: Apresentação e um procedimento. In: SCHNEUWLY, B.; DOLZ, J. et al. Gêneros orais e escritos na escola. Tradução e organização de: ROJO, R. H. R.; CORDEIRO, G. S. Campinas: Mercado de Letras, 2004. p. 81-108.

FERREIRA, A. L.; SPINILLO, A. G. Desenvolvendo a habilidade de produção de textos em crianças a partir da consciência metatextual. In: MALUF, M. R. (Org.). Metalinguagem e aquisição da escrita: Contribuições da pesquisa para a prática da alfabetização. São Paulo: Casa do Psicólogo, 2003. p. 119-148.

GOMBERT, J. E. Metalinguistic Development. Hertfordshire: Harverster Wheatsheaf, 1992.

KOCH, I. G. V. Introdução à linguística textual. 2. ed. São Paulo: WMF Martins Fontes, 2009.

KOCH, I. G. V.; ELIAS, V. M. Ler e compreender: Os sentidos do texto. 2. ed. 2. reimp. São Paulo: Contexto, 2008.

KOCH, I. G. V.; TRAVAGLIA, L. C. A. A coerência textual. São Paulo: Contexto, 2007.

LEITÃO, S. Composição textual: Especificidade da escrita argumentativa. In: CORREA, J.; SPINILLO, A.; LEITÃO, S. (Org.). Desenvolvimento da linguagem: Escrita e textualidade. Rio de Janeiro: FAPERJ/NAU, 2001. p. 117-141.

LEITÃO, S. Argumentação como processo de construção do conhecimento. In: ENCONTRO INTERNACIONAL LINGUAGEM, CULTURA E COGNIÇÃO, 2., 2003, Belo Horizonte. Anais do Encontro Internacional Linguagem, Cultura e Cognição-Reflexões para o ensino... Campinas, 2003.

LEITÃO, S. Argumentação e desenvolvimento do pensamento reflexivo. Psicologia: Reflexão e Crítica, v. 20, n. 3, p. 454-462, 2007. 
LEITÃO, S.; ALMEIDA, E. G. da S. A produção de contra-argumentos na escrita infantil. Psicologia: Reflexão e Crítica, v. 3, p. 351-362, 2000.

MARCUSCHI, A. L. Produção textual, análise de gêneros e compreensão. São Paulo: Parábola Editorial, 2008.

MOTA, M. Introdução - Desenvolvimento metalinguístico. In: MOTA, M. (Org.). Desenvolvimento Metalinguístico: Questões contemporâneas. São Paulo: Casa do Psicólogo, 2009. p. 9-18.

PINHEIRO, L. R. A produção de textos de opinião como expressão da consciência metatextual: Uma intervenção no contexto escolar. Tese (Doutorado) - Programa de Pós-Graduação em Educação, Universidade Federal do Paraná, Curitiba, 2012.

PINHEIRO, L. R.; GUIMARAES, S. R. K. A coerência e a coesão nos textos de opinião de alunos do $5^{\circ}$ ano de ensino fundamental. Estud. pesqui. psicol. [on-line], v. 13, n. 2, p. $500-523,2013$.

PINHEIRO, R.; LEITÃO, S. Consciência da "estrutura argumentativa" e produção textual. Psicologia: Teoria e Pesquisa, v. 23, n. 4, p. 423-432, out./dez. 2007.

RUSSELL, G. Print-based and visual discourses in schools: Implications for pedagogy. Discourse, v. 21, n. 2, p. 205-217, 2000.

SANTOS, S. L. A construção de argumentos no cotidiano. In: DIAS, M. G.; SPINILLO, A. (Org.). Tópicos em Psicologia Cognitiva. 2. ed. Recife: Ed. Universitária da UFPE, 2005. p. 44-79.

SIMPSON, A.; WALSH, M.; ROWSELL, J. The digital reading path: Researching modes and multidirectionality with iPads. Literacy, v. 47, n. 3, p. 123-130, 2013.

SOUZA, L. V. As proezas das crianças em textos de opinião. Campinas: Mercado das Letras, 2003. (Coleção Ideias sobre Linguagem).

SPINILLO, A. G. O uso de coesivos por crianças com diferentes níveis de domínio de um esquema narrativo. In: DIAS, M. G. B. B.; SPINILLO, A. G. (Org.). Tópicos em psicologia cognitiva. Recife: Editora da UFPE, 1996. p. 84-119.

SPINILLO, A. G. A produção de histórias por crianças: A textualidade em foco. In: CORREA, J.; SPINILlO, A. G.; LEITÃO, S. (Org.). Desenvolvimento da linguagem: Escrita e textualidade. Rio de Janeiro: Nau Editora, 2001. p. 73-116.

SPINILLO, A. G. A consciência metatextual. In: MOTA, M. (Org.). Desenvolvimento Metalinguístico: Questões contemporâneas. São Paulo: Casa do Psicólogo, 2009. p. 77-113.

SPINILLO, A. G.; MEDEIROS, A. P. Coesão e estrutura textual: Uma relação investigada a partir da escrita de textos narrativos e argumentativos. In: LUNA, M. J. M.; SPINILLO, A. G.; RODRIGUES, S. G. C. (Org.). Leitura e Produção de Texto. Recife: Editora da UFPE, 2010. p. 101-136. 
SPINILLO, A. G.; SIMÕES, P. U. O desenvolvimento da consciência metatextual em crianças: Questões conceituais, metodológicas e resultados de pesquisas. Psicologia: Reflexão e Crítica, v. 16, n. 3, p. 537-546, 2003.

THURLOW, C. Determined creativity: Language play in new media discourse. In: JONES, R. H. (Ed.). Discourse and creativity. New York: Routledge, 2012. p. 169-190.

TINDAL, G.; MARSTON, D. Technical adequacy of alternative reading measures as performance assessments. Exceptionality, v. 6, n. 4, p. 201-230, 1996.

TUNMER, W. E.; PRATT, C.; HERRIMAN, M. L. (Ed.). Metalinguistic awareness in children: Theory, research and implications. Berlin Heidelberg: Springer-Verlag, 1984.

WALSH, M. Literacy and learning with multimodal texts: Classroom glimpses. Synergy, v. 4, n. 1, p. 43-49, 2006.

WANG, M. J. Using multimodal presentation software and peer group discussion in learning English as a second language. Australasian Journal of Educational Technology, v. 27, n. $6,2011$.

Texto recebido em 30 de agosto de 2016. Texto aprovado em 30 de agosto de 2016. 